\title{
Synthesis of Platinum Cubes, Polypods, Cuboctahedrons and Raspberries Assisted by Cobalt Nanocrystals
}

\author{
Stephanie I. Lim ${ }^{1}$, Isaac Ojea-Jiménez ${ }^{1}$, Miriam Varon ${ }^{1}$, Eudald Casals ${ }^{1}$, Jordi Arbiol ${ }^{2,3}$, \\ Victor Puntes ${ }^{1,3 *}$ \\ ${ }^{1}$ Institut Català de Nanotecnologia, Barcelona, Spain. ${ }^{2}$ Institut de Ciència de Materials de \\ Barcelona, CSIC, Barcelona, Spain. ${ }^{3}$ Institut Català de Recerca i Estudis Avançats (ICREA), \\ Barcelona, Spain.*E-mail: Victor.Puntes.icn@uab.es
}

\section{Experimental Procedures}

Chemicals. Platinum (II) acetylacetonate ( $\mathrm{Pt}(\mathrm{acac})_{2}$, 98\%) was purchased from Strem Chemicals and used as received. Oleylamine (OAM, 70\%), 1,2-dichlorobenzene anhydrous (DCB, 99\%), oleic acid (OA, 99\%), 1,2-hexadecanediol (HDD, 90\%), cobalt (II) acetylacetonate $\left(\mathrm{Co}(\mathrm{acac})_{2}, 97 \%\right)$, cobalt carbonyl moistened with $5-10 \%$ hexane $\left(\mathrm{Co}_{2}(\mathrm{CO})_{8}, 90\right.$ $95 \%)$, cobalt (II) chloride $\left(\mathrm{CoCl}_{2}, 98 \%\right)$ and super-hydride ${ }^{\circledR}$ lithium triethylborohydride (in $1 \mathrm{M}$ THF) were purchased from Sigma-Aldrich and used as received. All chemicals were stored and prepared for synthesis in a UNIlab MBraun glovebox unless otherwise stated. The synthesis of Co NCs [Puntes, V. F.; Krishnan, K. M.; Alivisatos, A. P. Science 2001, 291, 2115] and Au NCs [Hiramatsu, H.; Osterloh, F. E. Chem. Mater. 2004, 16, 2509] follow the previously reported procedures and the $\mathrm{NC}$ purification was performed in the presence of methanol or acetone followed by dispersion in DCB or toluene, respectively.

Instrumentation. Transmission electron microscopy (TEM) analysis was performed on a JEOL 1010 with an accelerating voltage of $80 \mathrm{kV}$. High resolution TEM (HRTEM) analysis was performed on a JEOL 2100 with an accelerating voltage of $200 \mathrm{kV}$ equipped with an energy-dispersive X-ray spectroscopy (EDX) detector. The Pt NCs were drop-cast onto a carbon coated grid and allowed to air dry under ambient conditions. X-ray diffraction (XRD) data were collected on a PANalytical X'Pert diffractometer using a $\mathrm{Cu} \mathrm{K} \alpha$ radiation source $(\lambda=1.541 \AA)$. In a typical experiment, the $2 \theta$ diffraction (Bragg) angles were measured by scanning the goniometer from $25^{\circ}$ to $100^{\circ}$ at a speed of $0.021^{\circ} \mathrm{s}^{-1}$. The samples were prepared by precipitating the $\mathrm{Pt} \mathrm{NCs}$ in the presence of methanol or ethanol followed by brief centrifugation to ensure that all the NCs precipitated. The supernatant was discarded and the samples were dried under nitrogen before smearing onto (510) silicon wafers ( $3^{\circ}$ off axis) for XRD analysis. Estimates of nanocrystal size were obtained using the Scherrer equation $(d=$ $(K \lambda) / \beta \cos \theta)$ where $d$ is the mean crystallite dimension, $K$ is the shape factor $(0.9), \lambda$ is the $\mathrm{X}$ - 
ray wavelength, $\beta$ is the line broadening at full width half maximum (FWHM) (radians) and $\theta$ is the Bragg angle. The peak positions were determined using the $X^{\prime}$ Pert HighScore program and compared before and after baseline correction. Vegard's law of alloy nanocrystals was considered for a slight shift in the $2 \theta$ Bragg peaks when compared to those for bulk Pt. Induced coupled plasma-mass spectroscopy (ICP-MS) was performed using an ICP-MS Agilent instrument (Model: 7500cx) with a detection limit of $0.02386 \mathrm{ppb}$. For each sample, the assynthesized NCs, the purified NCs and the supernatant from the purification were all subjected to ICP-MS analysis. Aliquots of the Pt NC samples were dissolved in concentrated aqua regia, which was then heated to ensure complete dissolution of all the metals, and diluted to an optimal concentration for ICP-MS analysis. Ga was used as the internal standard and the integration time/point and time/mass were $0.1 \mathrm{sec}$ and $0.3 \mathrm{sec}$, respectively with a $3 \mathrm{x}$ repetition.

\section{Synthesis.}

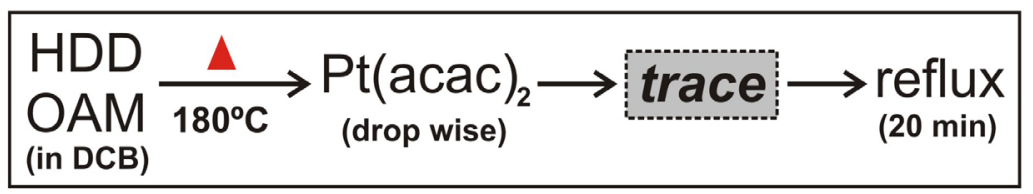

Scheme S1. A general synthesis procedure where the only variable is the different traces added to the synthesis.

General Synthesis: Unless otherwise stated, all syntheses were performed under an argon atmosphere using the standard Schlenk-line setup. In a typical synthesis, a solution containing $92 \mathrm{mg}$ of HDD $(0.36 \mathrm{mmol}), 45 \mu \mathrm{L}$ of OAM and $10 \mathrm{~mL}$ of DCB was added to a 3-neck roundbottom flask equipped with a condenser. The solution temperature was increased to $180{ }^{\circ} \mathrm{C}$ using a glycerol oil bath over a time period of $\sim 30-60 \mathrm{~min}$. Once the boiling temperature of DCB was reached, a $3 \mathrm{~mL}$ solution of DCB containing $45 \mathrm{mg}$ of $\mathrm{Pt}(\mathrm{acac})_{2}(0.11 \mathrm{mmol})$ was added drop-wise to the solution at a rate of $0.5 \mathrm{~mL} / \mathrm{min}$. $100 \mu \mathrm{L}$ of trace $(0.0018 \mathrm{mmol})$ was then added immediately to the solution. The solution was refluxed at $180{ }^{\circ} \mathrm{C}$ for $20 \mathrm{~min}$ and gradually cooled down to room temperature before being transferred to an argon filled vial. In order to remove the excess capping/reducing agent or ions, the Pt NCs were purified by precipitation in methanol (or ethanol), followed by brief centrifugation and redispersion in DCB.

Temperature Dependent Synthesis: To study the effect of temperature on the synthesis of Pt $\mathrm{NCs}$, the reaction was performed at $140{ }^{\circ} \mathrm{C}$ and $180{ }^{\circ} \mathrm{C}$. In a typical synthesis, $92 \mathrm{mg}$ of HDD, $45 \mu \mathrm{L}$ of OAM and $100 \mu \mathrm{L}$ of pre-synthesized (unpurified) Co NCs $(0.0018 \mathrm{mmol})$ were added to $10 \mathrm{~mL}$ of DCB. The temperature of the solution was increased to $140{ }^{\circ} \mathrm{C}$ where $3 \mathrm{~mL}$ of 
$\operatorname{Pt}(\mathrm{acac})_{2}(45 \mathrm{mg})$ was added drop-wise at rate of $0.2 \mathrm{~mL} / \mathrm{min}$. After adding the $\mathrm{Pt}(\mathrm{acac})_{2}$, the solution was heated for $30 \mathrm{~min}$ at $140{ }^{\circ} \mathrm{C}$ after which an aliquot was taken out for TEM analysis. The temperature was then increased to $180{ }^{\circ} \mathrm{C}$ where the remaining solution refluxed for another 30 min before gradually cooling down to room temperature.

\section{Different Synthesis Conditions:}

Synthesis of Pt NCs in aqueous media: [Pt NCs (Aq)]

The citrate capped Pt NCs were synthesized following the previously reported procedure [Xu, $\mathrm{S}$. L.; Cui, H. Luminescence 2007, 22, 77] with some slight modifications (Figure 8A). Briefly, $\mathrm{K}_{2} \mathrm{PtCl}_{4}(0.03 \mathrm{mmol})$ was added to $100 \mathrm{~mL}$ of deionized water in a round bottom flask and boiled at $100{ }^{\circ} \mathrm{C}$. A $5 \mathrm{~mL}$ solution of trisodium citrate $(1 \%)$ was then added all at once and the solution was refluxed for 1 hour before being gradually cooled down to room temperature.

Changing the sequential addition of $\mathrm{Pt}(\mathrm{acac})_{2}$ : [ $\mathrm{Pt}(\mathrm{acac})_{2}$ added at $\left.\mathrm{RT}\right]$

For the synthesis shown in Figure $8 \mathrm{~B}$, the $\mathrm{Pt}(\mathrm{acac})_{2}$ precursor $(45 \mathrm{mg}$ in $3 \mathrm{~mL} \mathrm{DCB})$ was added along with OAM and HDD ( $45 \mu \mathrm{L}$ OAM and $93 \mathrm{mg}$ HDD) in $10 \mathrm{~mL} \mathrm{DCB}$ at room temperature. The solution was then heated to $180{ }^{\circ} \mathrm{C}$ where $100 \mu \mathrm{L}$ of $\mathrm{Co}_{2}(\mathrm{CO})_{8}(0.0018 \mathrm{mmol})$ was added immediately. The reaction was refluxed for $30 \mathrm{~min}$ at $180{ }^{\circ} \mathrm{C}$ before being gradually cooled down to room temperature.

Changing the sequential addition of pre-synthesized Co NC and reaction time: [Co NCs added at RT, TEM@2hrs]

For the synthesis shown in Figure 8C, the unpurified pre-synthesized Co NCs were added at the beginning of the reaction. In a typical synthesis, $90 \mathrm{mg}$ of HDD, $45 \mu \mathrm{L}$ of OAM and $100 \mu \mathrm{L}$ of pre-synthesized Co NCs (unpurified, $0.0018 \mathrm{mmol}$ ) were added to $10 \mathrm{~mL}$ DCB. The temperature of the solution was increased to $180^{\circ} \mathrm{C}$ where $3 \mathrm{~mL}$ of Pt $(\mathrm{acac})_{2}(45 \mathrm{mg})$ was added drop-wise $(0.2 \mathrm{~mL} / \mathrm{min})$. The solution was refluxed for $2 \mathrm{hrs}$ at $180{ }^{\circ} \mathrm{C}$ and gradually cooled down to room temperature.

Varying the concentration of pre-synthesized Co NC and HDD and reaction time: [[Co NCs] $\uparrow$ ] For the synthesis shown in Figure 8D, the concentration of the pre-synthesized Co NC trace was increased 10x and added at the beginning of the reaction. In a typical synthesis, $30 \mathrm{mg}$ of HDD and $45 \mu \mathrm{L}$ of OAM were added to $9 \mathrm{~mL}$ DCB and $1 \mathrm{~mL}$ of pre-synthesized Co NCs (unpurified, $0.018 \mathrm{mmol})$. The solution was heated up to $180{ }^{\circ} \mathrm{C}$ where $40 \mathrm{mg}$ of $\mathrm{Pt}(\mathrm{acac})_{2}$ in $3 \mathrm{~mL} \mathrm{DCB}$ was added drop-wise at a rate of $0.1 \mathrm{~mL} / \mathrm{min}$. The solution was refluxed for $2 \mathrm{hrs}$ at $180^{\circ} \mathrm{C}$ and gradually cooled down to room temperature.

Varying the concentration of OAM and reaction time: [[OAM] $\uparrow]$

For the synthesis shown in Figure $8 \mathrm{E}$, the concentration of OAM was increased $2.2 \mathrm{x}$. In a typical synthesis, $94 \mathrm{mg}$ of HDD and $100 \mu \mathrm{L}$ of OAM was added to $10 \mathrm{~mL}$ DCB. The solution was heated up to $180{ }^{\circ} \mathrm{C}$ where $45 \mathrm{mg}$ of $\mathrm{Pt}(\mathrm{acac})_{2}$ in $3 \mathrm{~mL}$ DCB was added drop-wise at a rate of $0.6 \mathrm{~mL} / \mathrm{min} .100 \mu \mathrm{L}$ of $\mathrm{Co}_{2}(\mathrm{CO})_{8}(0.0018 \mathrm{mmol})$ was added immediately and the solution was refluxed for $50 \mathrm{~min}$ at $180{ }^{\circ} \mathrm{C}$ and gradually cooled down to room temperature.

Addition of Oleic Acid (OA) and Oleylamine (OAM): [OAM+OA]

For the synthesis shown in Figure 8F, both OA and OAM were added. In a typical synthesis, 93 $\mathrm{mg}$ of HDD, $45 \mu \mathrm{L}$ of OAM and $45 \mu \mathrm{L}$ of OA were added to $10 \mathrm{~mL}$ DCB. The solution was heated up to $180{ }^{\circ} \mathrm{C}$ where $45 \mathrm{mg}$ of $\mathrm{Pt}(\mathrm{acac})_{2}$ in $3 \mathrm{~mL}$ DCB was added drop-wise at a rate of $0.4 \mathrm{~mL} / \mathrm{min} .100 \mu \mathrm{L}$ of $\mathrm{Co}_{2}(\mathrm{CO})_{8}(0.0018 \mathrm{mmol})$ was added immediately and the solution was refluxed for $15 \mathrm{~min}$ at $180^{\circ} \mathrm{C}$ and gradually cooled down to room temperature. 


\section{Vegard's Law}

The definition of Vegard's law provided by Ashcroft et al. [Phys. Rev. A 1991, 43, 3161] is "an approximate empirical rule which holds that a linear relation exists, at constant temperature, between the crystal lattice constant of an alloy and the concentrations of the constituent elements." The lattice parameter $(a)$ of Pt and Co NCs used in this calculation are: $3.917 \AA$ for 100\% Pt and $3.533 \AA$ for $100 \%$ Co NCs [Nam, K. M.; Shim, J. H.; Ki, H.; Choi, S.; Lee, G.; Jang, J. K.; Jo, Y.; Jung, M.; Song, H.; Park, J. T. Angew. Chem. 2008, 120, 9646]. For $a=$ $3.905 \AA$ ( $\mathrm{Pt} \mathrm{NCs}$ synthesized in the presence of $\mathrm{Co}$ ), the \% Co was calculated by: $x=\frac{100 \%(3.917-3.905)}{3.917-3.533}$ where $x=3.1 \%$ Co.

\section{$\underline{\text { ICP-MS Analysis }}$}

\begin{tabular}{|c|c|c|c|c|c|c|}
\hline $\begin{array}{c}\text { TEM } \\
\text { Images }\end{array}$ & $\begin{array}{c}\text { Metallic } \\
\text { Trace }\end{array}$ & Sample Description & $\begin{array}{c}\text { Co } \\
\text { ppm }\end{array}$ & $\begin{array}{c}P t \\
p p m\end{array}$ & $\% \mathrm{Co}$ & $\% P t$ \\
\hline \multirow{3}{*}{ 8e8f } & $\mathrm{Co}_{2}(\mathrm{CO})_{8}$ & As synthesized NCs & 6.40 & 1048.0 & 1.98 & 98.02 \\
\hline & $\mathrm{Co}_{2}(\mathrm{CO})_{8}$ & Purified NCs & 4.65 & 559.0 & 2.68 & 97.32 \\
\hline & $\mathrm{Co}_{2}(\mathrm{CO})_{8}$ & Supernatant from purification & 0.38 & 473.8 & 0.26 & 99.74 \\
\hline \multirow{3}{*}{ 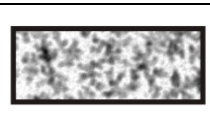 } & a) $\mathrm{Co}(\text { acac })_{2}$ & As synthesized NCs & 4.90 & 607.5 & 2.60 & 97.40 \\
\hline & ${ }^{\text {a) }} \mathrm{Co}(\mathrm{acac})_{2}$ & Purified NCs & 0.10 & 111.5 & 0.30 & 99.70 \\
\hline & ${ }^{\text {a) }} \mathrm{Co}(\mathrm{acac})_{2}$ & Supernatant from purification & 4.13 & 376.3 & 3.50 & 96.50 \\
\hline \multirow{3}{*}{ Sed838 } & ${ }^{b)} \mathrm{Co}(\mathrm{acac})_{2}$ & As synthesized NCs & 8.15 & 1007.0 & 2.61 & 97.39 \\
\hline & b) $\mathrm{Co}(\mathrm{acac})_{2}$ & Purified NCs & 6.75 & 449.5 & 4.74 & 95.26 \\
\hline & b) $\mathrm{Co}(\mathrm{acac})_{2}$ & Supernatant from purification & 0.13 & 500.0 & 0.08 & 99.92 \\
\hline
\end{tabular}

Table S1. ICP-MS analysis comparing the atomic \% Co and \% Pt obtained for three different synthesis using $\mathrm{Co}_{2}(\mathrm{CO})_{8}$ and $\mathrm{Co}(\mathrm{acac})_{2}$ as traces. In each batch of syntheses, the assynthesized NCs, the purified NCs and the supernatant from the purification were subjected to ICP-MS analysis. Two samples from the $\mathrm{Co}(\mathrm{acac})_{2}$ were chosen for analysis due to the different morphologies observed in TEM. $\left({ }^{\mathrm{a})} \mathrm{Co}(\mathrm{acac})_{2}\right.$ shows polypod structure and ${ }^{\mathrm{b})} \mathrm{Co}(\mathrm{acac})_{2}$ shows cemented cubes structure). Overall, the experimentally determined compositions are in agreement with the theoretical proportion $\mathrm{Co}$ and $\mathrm{Pt}$ amounts that were added to a typical synthesis. (theoretical: 2\% Co and 98\% Pt). The difference in proportion between the added and the measured element concentration is in the solution in ionic form. 

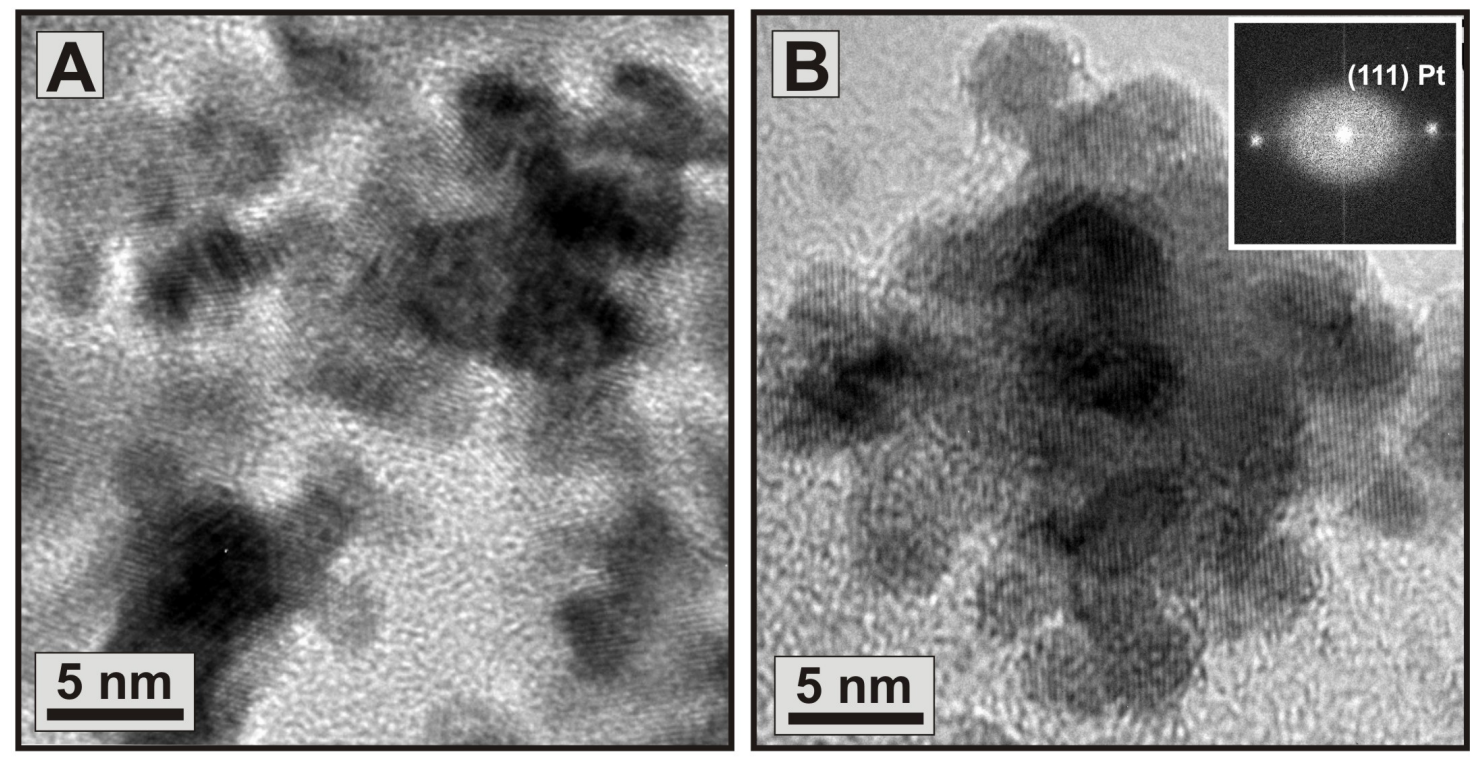

Figure S1. HRTEM images of the polypods oriented attached into a multi-crystalline (A) and single-crystalline (B) structure. The FFT pattern in (B) indicates that the (111) planes are perfectly aligned and have a single crystal structure.

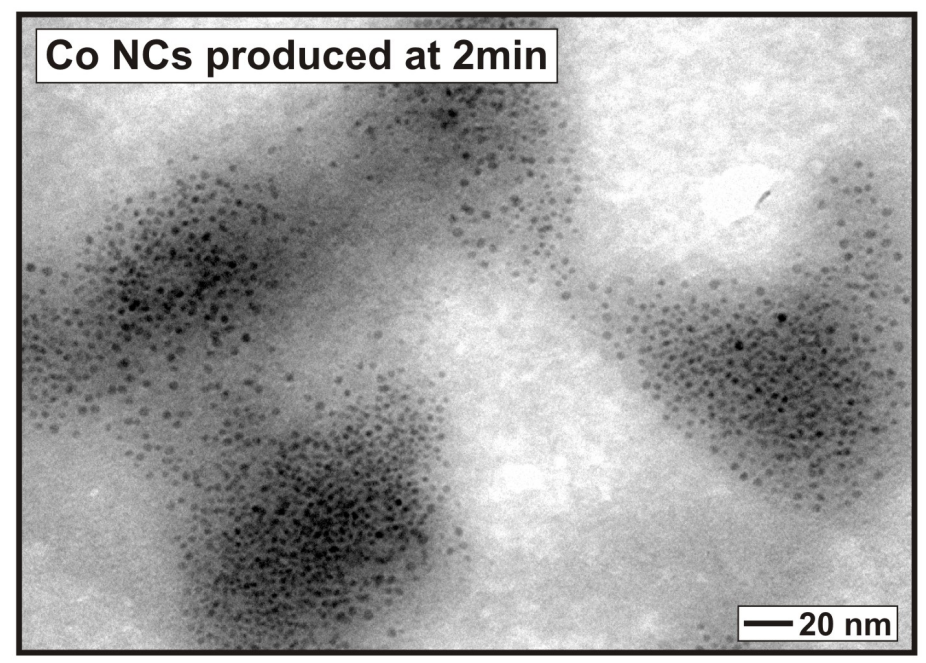

Figure S2. A control experiment demonstrating the formation of Co NCs within a 2 min reaction time. The synthesis follows the experimental procedures reported in the paper but in the absence of $\mathrm{Pt}(\mathrm{acac})_{2}$. For example, upon heating the solution containing DCB, HDD and $\mathrm{OAM}$ to $180^{\circ} \mathrm{C}, 100 \mu \mathrm{L}$ of $\mathrm{Co}_{2}(\mathrm{CO})_{8}$ was added immediately. The solution was heated for 2 min at $180^{\circ} \mathrm{C}$ and transferred to an argon filled vial immediately. The background contrast is due to the excess HDD and OAM still remaining at short reaction times. 


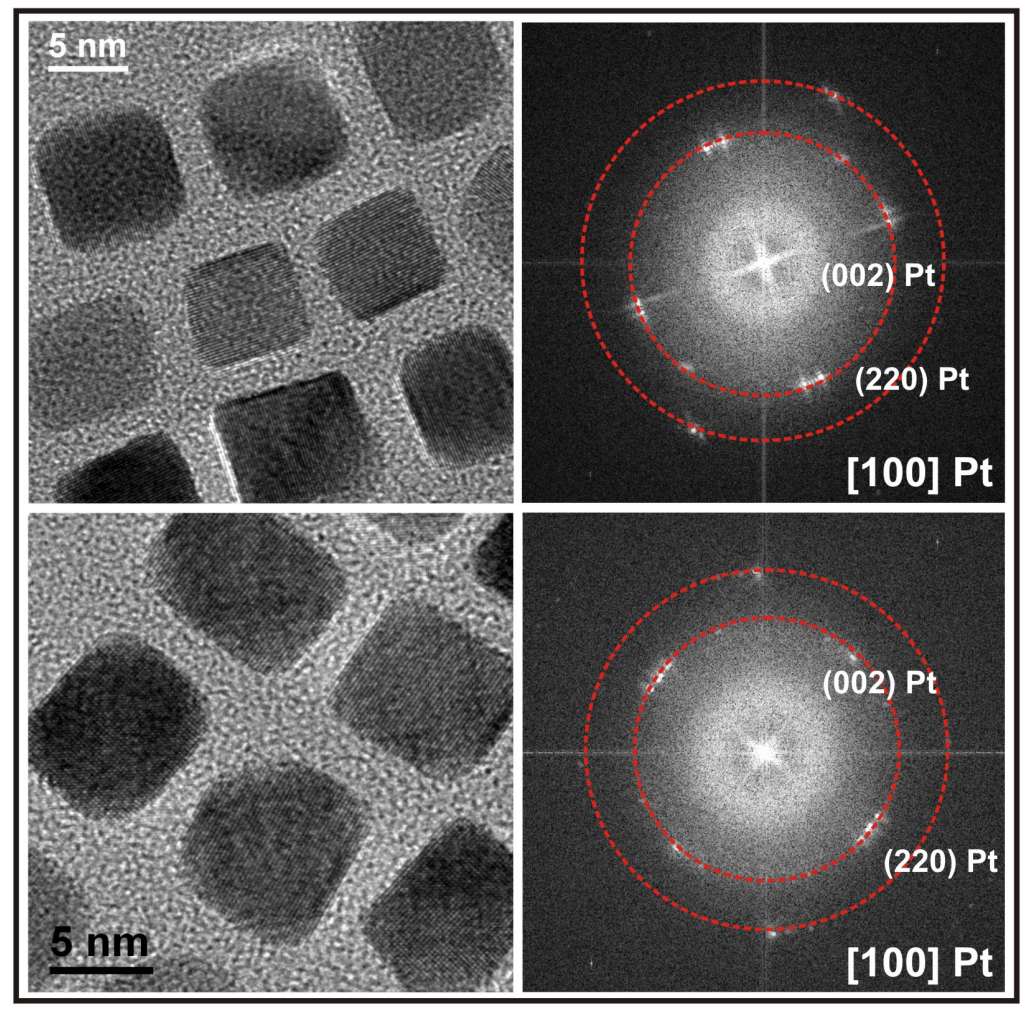

Figure S3. HRTEM images and their corresponding FFT patterns for the Pt NCs synthesized in the presence of a $\mathrm{Co}_{2}(\mathrm{CO})_{8}$ metallic trace. Both examples show that the $\mathrm{Pt} \mathrm{NC}$ cubes have a preferential orientation along the [100] zone axis, showing facets on the $\{100\}$ planes.
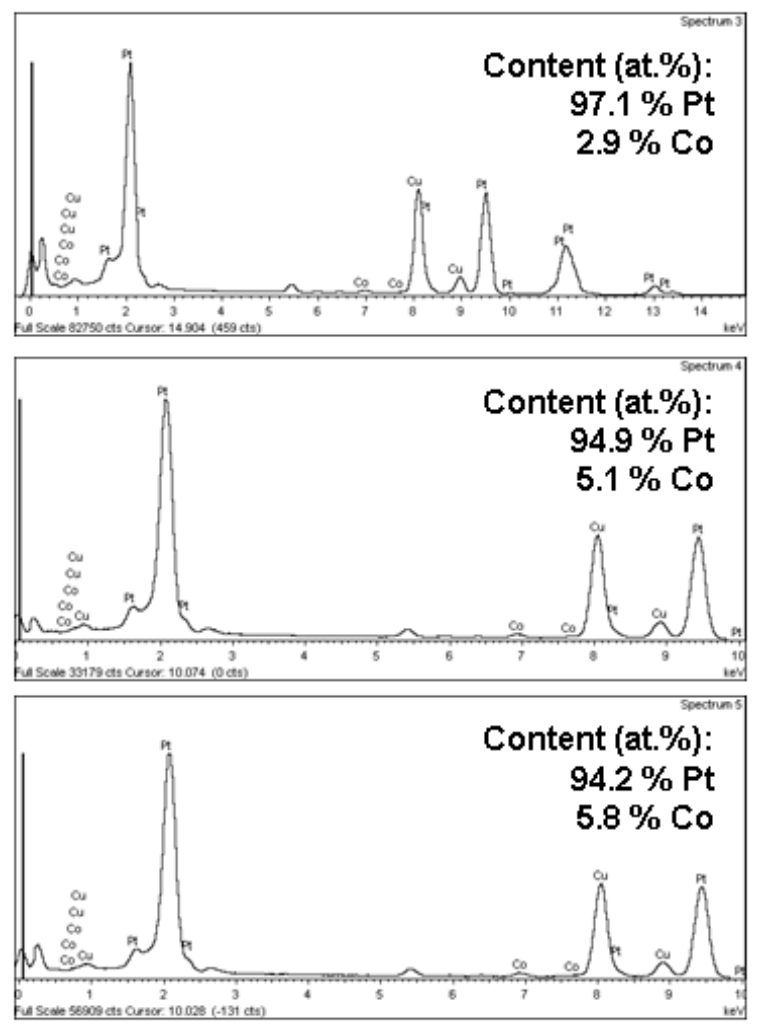

Figure S4. EDX spectra obtained on different areas of the Pt NC samples synthesized in the presence of a $\mathrm{Co}_{2}(\mathrm{CO})_{8}$ metallic trace. The Pt NCs were purified prior to EDX analysis to remove all excess ions and capping agents. Notice that the Co amount varies from 3\% to $6 \%$ depending on the different areas of the grid. The average content is around $4.5 \%$. 